DIVISION OF THE HUMANITIES AND SOCIAL SCIENCES

CALIFORNIA INSTITUTE OF TECHNOLOGY

PASADENA, CALIFORNIA 91125

THE CONTROL OF GAME FORM RECOGNITION IN EXPERIMENTS: UNDERSTANDING DOMINANT STRATEGY FAILURES IN A SIMPLE TWO PERSON "GUESSING" GAME

Eileen Chou

Margaret McConnell

Rosemarie Nagel

Charles R.Plott

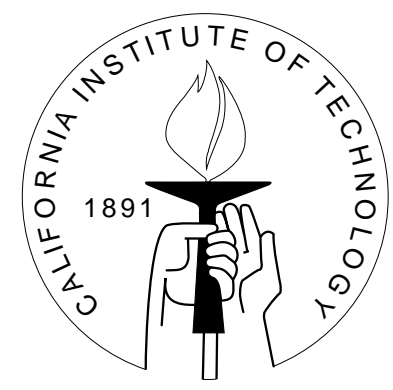

SOCIAL SCIENCE WORKING PAPER 1274 


\title{
The control of game form recognition in experiments: Understanding dominant strategy failures in a simple two person "guessing" game
}

\author{
Eileen Chou Margaret McConnell Rosemarie Nagel Charles R.Plott
}

\begin{abstract}
The paper focuses on instructions and procedures as the reasons that subjects fail to behave according to the predictions of game theory as observed in two person guessing game experiments. In this game, each of two people has to choose simultaneously a number between 0 and 100 . The winner is the person whose chosen number is the closest to $2 / 3$ of the average of the two numbers. The weakly dominant strategy is zero. Because of the simplicity of the game (once it is understood), the widespread failure of subjects to choose the weakly dominant strategy has been interpreted as evidence of some fundamental inability to behave strategically.

The experiments reported here demonstrate that the failure to act strategically is related to how the game is presented. Several different presentations are studied. Some subjects fail to recognize the game form when it is presented abstractly. When the game is transformed into the simple isomorphic game and presented in a familiar context, subjects do choose weakly dominant strategies. Suggestions for better experiment control are given.
\end{abstract}

JEL classification numbers:

Key words: experiments 


\title{
The Control of Game Form Recognition in Experiments: Understanding Dominant Strategy Failures in a Simple Two Person “Guessing” Game.
}

\author{
Eileen Chou, Margaret McConnell, Rosemarie Nagel and Charles R. Plott`
}

\section{INTRODUCTION}

Evidence from the two person guessing game ${ }^{1}$ (a "beauty contest" game) demonstrates a widespread failure of individuals to choose a weakly dominating strategy (Grosskopf and Nagel, forthcoming GEB). The game appears simple once it is understood. Each of two people is instructed to simultaneously choose a number between 0 and 100. The chosen numbers are revealed and the winner is the person whose chosen number is the closest to $2 / 3$ of the average of the two numbers. The weakly dominant strategy is zero but frequently it is not chosen. The behavior is interpreted as a clear rejection of game theory.

The failure of game theory has been attributed to a cognitive bias in which people underestimate their own influence on the outcome of a game (GN). Indeed, the authors suggest that this underestimation bias, if wide spread, might replace game theory as an explanation of over-crowding and congestion (GN). Our results support a more optimistic outlook for game theory. We demonstrate that the absence of appropriate strategic behavior is not so much due to an inability to think or act strategically as it is a failure to recognize and understand the game form itself. That is, subjects have an incomplete, inaccurate or perhaps absent grasp of the relationships between the choices made in the game and the incentives, which we call "game form recognition." The paper contains two contributions. First, we advance the idea that a failure of "game form recognition" is an explanation of the phenomena. Secondly, we explore alternative instructions and procedures as tools for guiding tests of game theory.

\footnotetext{
- Chou: Kellogg School of Management, Northwestern University, McConnell and Plott: Division of Humanities and Social Sciences, California Institute of Technology, Nagel: Universitat Pomepu Fabra, Department of Economics. The financial support of the Caltech Laboratory of Experimental Economics and Political Science is gratefully acknowledged. Nagel acknowledges the Human Science Frontier Program and the hospitality of HSS Caltech. The authors wish to thank the students in the Caltech Experimental Economics class for many helpful comments and discussions.

${ }^{1}$ Guessing games, with $n>2$, have been studied by many authors (e.g., Nagel 1995, Ho, Camerer Weigelt (1998), Bosch et al. ((2002), Weber (2003) etc); for surveys see Nagel (1998), Camerer (2003). The 2 person game by Costa-Gomes and Crawford (2006) is different in structure to the two person guessing game studied here since in their game both players attempt to choose a number closest to $p$ times the other's chosen number. $\mathrm{P}$ is different for the two players and also the interval to choose a number from may differ. The $n>2$ game and the last mentioned game are dominant solvable. A so-called level-k model has been applied by the above authors to successfully explain the observed behavior (see also Stahl (1996, 1998), or a one parameter hierarchical model by Camerer et al. (2004). Weakly dominant strategies are typically chosen in $10-20 \%$.
} 
The paper is divided into four sections. The first is an overview that explains the nature of the results. The second is a section on the experimental design that lists experiments. The third section, which contains the statements of results, is partitioned into two subsections. Subsection A contains the first tests of whether the failure of game theory results from a lack of game form recognition. Subsection B is an analysis of instruction and procedural failures. The loss of experimental control we observe is striking. This presents an opportunity to explore modifications of the instructions and procedures that may be appropriate for addressing the failure to recognize the game form. The final section is a discussion of conclusions.

\section{OVERVIEW}

The research began with a discussion of a question posed by GN. What would happen if you simply told subjects that the person who chooses the lower number wins? Such a hint falls short of telling them that the weakly dominant strategy is to choose zero but it makes the strategic structure clear. A presumption would be that with such a hint, subjects would all behave according to game theoretic predictions. But, if game theory works perfectly when such a hint is provided, it would seem that the failure of game theory reported in the literature turned more on subjects' perception of the nature of the exercise than on the psychological bias that was offered as an explanation. The hint has nothing to do with features of the psychological explanation so the power of the hint, if such power exists, would be working through some alternative mechanism. Our experiments began with an effort to determine whether the hint has the expected effect.

The initial experiment was designed for the Caltech subject pool. We developed three treatments. One treatment had subjects participating with instructions similar to those used in the literature. A second treatment added a strong hint: "Notice that the person who chooses the lower number always wins.” A third treatment, which is not discussed here, had groups of three choosing in order to test whether groups would be better at game theory than individuals.

In the Caltech subject pool, the hint had a definite impact. Without the hint, dominated strategies were frequently chosen, but with the hint, the choice was almost always the dominating strategy. It seemed that our major hypothesis was supported; game form recognition and not cognitive biases was operating in GN. As a test of robustness we then went to a completely different subject pool in a local community college. The same instructions and procedures were used. The dramatic result was that the hint made little difference in behavior and that with or without the hint subjects tended not choose the weakly dominating strategy.

A casual examination of the data leads to the suggestion that we had lost experimental control. Subjects were not playing the game as we constructed it. After the experiment, we administered a questionnaire to help us understand why. The data from the experiments and the answers to the questionnaire lead to a series of experiments with subjects from the local community college, each of which attempted to isolate the source 
of lost control and to correct it. Thus, a research design that began as a simple test transformed itself into exploratory research.

We first present our major conclusion below. Our conclusion is that the data from (GN) should not be interpreted as a rejection of game theory or as a manifestation of a cognitive bias. Instead, subjects did not understand the game form. Having presented the substantive result of the research, the paper turns to our analysis, including the changes in procedures and the results of those changes. We present these details as a comment on experimental procedures and the subtle features of attention and perception that are at play when one attempts to test game theory. Procedures that appear as obvious solutions do not work and those that do are inconsistent with accepted procedures for conducting experiments in economics.

\section{EXPERIMENTAL DESIGN}

Our exploratory experimental design resulted in a series of instructions and procedures. Table 1 lists all experiments. Two subject pools were used, Caltech and a local community college, along with one experiment conducted in Spain, at Universitat Pompeu Fabra. The instructions implemented two different descriptions of the underlying game. One is abstract and is called the Beauty Contest Game (BCG) and the other is an isomorphic game placed in the context of a battle, called Battle. The BCG came in two forms, one with no "hint" and one with the hint: "Notice how simple this is: the lower choice of the two numbers will always win”. Four sets of procedures were used, we call them the Baseline BCG Protocol, the Simplified Protocol, the Battle Protocol and the Battle and Simplified Protocol (this incorporates both the Battle Protocol and the Simplified Protocol). Each was developed in response to the observations of experiments and follow up questions of subjects. These will be explained below.

In order to facilitate an understanding of the design, the discussion will proceed in the order with which it developed. The first set of instructions and procedures is designed as the Baseline Protocol and were administered in four experiments; one at Caltech, one in Spain at Universitat Pompeu Fabra, and three at a local community college. This protocol and set of instructions contained neutral language that precisely described the exercise. Within the same experimental session, one group had the instructions with no hint while a randomly selected second group had the same instructions with a hint. These instructions are in the Appendix. The first experiments were conducted at Caltech. The other subject pools were used as checks on the robustness of the results from Caltech.

The decisions by subjects in the first experiment at the community college tended to be dramatically different from the Caltech and Spanish subject pools and motivated the construction of a questionnaire that might help us understand the reason for the difference. We returned to the class and administered the questionnaire. The questionnaire is Table 2-A. In order to illustrate the loss of experimental control, we include a selection of responses to the questionnaire as Table 2-B. It seemed clear to us that the instructions were not effective in conveying an understanding of the game. Experimental control was lost because almost all subjects were not participating in the 
experiment that we designed. The reader can glance over the data in Table 2-B and develop an independent judgment about the nature of the answers.

In response to the questionnaire, we developed a set of protocols and instructions called the Simplified Protocol. This set of instructions used the words game, strategy, and other language to emphasize that the subjects were participating in a strategic situation. The instructions were shortened. Bullets were used to emphasize important points so reading was minimal. An example was put on the board. The experimenters carried and showed a large amount of cash and wore Caltech t-shirts to focus the subjects on the task and its research nature. In addition, the instructor of the class introduced the experimenters and emphasized that it was for real money and that they should pay attention.

Experiments with instruction under the Simplified Protocol seemed to have little effect and the comments on the instruction form suggested that subjects did not understand the instructions.

In response to this possibility, we developed the "Battle" Scenario which we call the Battle Protocol. The possible usefulness of a non-abstract content in instructions has been recognized in the literature. ${ }^{2}$ The "Battle" Scenario we employ is a game that is isomorphic to the BCG with a hint that is dictated by the idea of facilitating the recognition of game form. The instructions are dramatically simplified. Subjects are told that they must decide where to place their troops on a hill. They have a randomly determined opponent in the room who will also make such a choice and that the person who places their troops highest will win the battle. The hill is 100 feet high.

Our last modification to instructional protocol consisted of administering the BCG under the Simplified Protocol after the administration of the battle game under the Battle Protocol. That is, subjects participated in the Battle Protocol experiment and then later participated in the Simplified Protocol experiment. We call this combined protocol the Battle and Simplified Protocol. Our hypothesis was that subjects would be more able to recognize the form of the game in the abstract BCG after participating in the isomorphic battle game.

\footnotetext{
${ }^{2}$ Cooper and Kagel (2003) point toward the psychology literature which suggests that the context of in which a game is presented affects behavior. Cooper and Kagel find that a using a meaningful context to present a game facilitates learning across games. The general importance of instructions and procedures in economics experiments is also illustrated in Plott and Zeiler (forthcoming).
} 


\section{RESULTS}

\section{A. Cognitive Bias and Game Theory Rejection vs Game Form Recognition and Experimental Control}

We use three different measures of subjects' behavior in the game. The first is the number of subjects who chose the weakly dominant strategy. ${ }^{3}$ Because we are concerned that subjects might not have understood that they can chose 0 and in order to include considerations of closeness to equilibrium in our analysis, we include the share of students choosing a number less than or equal to 5 as an approximation of the weakly dominant strategy. While we report both measures in the tables, the numbers discussed here refer to this approximation of the weakly dominant strategy. Another measure is the average number chosen. This measure allows for an examination of whether subjects' recognition of the game form (from one set of instructions to another by different subjects) goes in gradual steps or whether subjects make a discontinuous jump to a different mode of behavior. If subjects' behavior represents discontinuous "Eureka” moments of recognition of the weakly dominant strategy, we would expect some sort of jump and not expect average choices in the BCG to mirror the number of subjects choosing the weakly dominant strategy.

Result 1: Departures from the predictions of game theory in the 2-person beauty contest game are due to loss of experimental control and lack of game form recognition rather than cognitive bias.

This conclusion is initially supported in Table 4 by comparing the results from Caltech subjects who received a hint to Caltech subjects who receive no hint . In the baseline treatment, $50 \%{ }^{4}$ of subjects choose the weakly dominant strategy. When including the hint, close to $90 \%$ of the subjects chose the weakly dominant strategy. This evidence provides strong support that subjects' behavior is not consistent with a cognitive bias, but instead that they do not recognize the game form. Once they are provided with the clarifying hint, they chose the weakly dominant strategy.

While there is a clear loss of experimental control with the community college subjects, the results of the exploratory research strongly support the hypothesis that their behavior was due to a lack of game form recognition. Without the hint, none of the subjects choose the weakly dominant strategy. When we consider the approximate measure, $15 \%$ of subjects chose a weakly dominant strategy. In addition, introducing the clarifying hint makes no difference on subjects' behavior: with the hint only $7 \%$ of subjects chose exactly the weakly dominant strategy while $13 \%$ chose close to the weakly dominant strategy.

\footnotetext{
${ }^{3}$ Subjects' choices in the battle game are converted by subtracting them from 100 so that they may be compared with subjects' choices in the beauty contest game.

${ }^{4}$ Note that GN report that their students subject choose 0 in $10 \%$ while the economic professors choose in $37 \%$. Thus, the GN experiments are consistent with what we report. The performance of subjects who might be expected to have greater skills at reading and interpreting instructions is closer to the predictions of game theory.
} 
Strikingly, when the instructions were given in the form of an isomorphic battle, the instance of strategic behavior went up to 65\%. These changes in instructions and procedures involved no changes in incentives, information or subject pool. The only feature seems to be the clarity of the game and related incentives. The result is that strategic behavior as predicted by game theory emerged as the fundamental tendency. Had subjects been incapable of strategic thinking along the lines of game theory, such clarification of rules and incentives should have had no effect.

\section{B. An Anatomy of Loss of Experimental Control and Attempted Corrections}

The answers to the questionnaire designed to uncover the reasons for loss of experimental control among the community college subjects suggested that the behavior reflected aspects of design and execution of the experiment rather than cognitive incapacity or preferences. We therefore undertook exploratory research with these subjects to attempt to develop some tools to address loss of experimental control and problems of game form recognition.

Result 2: Obvious adjustments to instructions do not show a significant improvement in facilitating subjects' game form recognition.

The Simplified protocol represents a comprehensive effort to simplify instructions and improve the conditions under which the game is implemented. As can be seen in Table 5, these changes have little effect on game form recognition, except where the clarifying hint is also included. With no hint, subjects choose the weakly dominant strategy only $5 \%$ of the time. When they received a hint, subjects chose the weakly dominant strategy $11 \%$ of the time and close to the weakly dominant strategy $32 \%$ of the time. ${ }^{5}$

These results suggest that the changes to instructions may have been able to address more fundamental problems of loss of experimental control, such as subjects' lack of engagement with the experiment. Since the hint offers non-trivial assistance in discovering the weakly dominant strategy, we take the lack of response to the hint in the Baseline Protocol with subjects' comments as evidence that subjects were not engaged with the experiment. The simplification of instructions clearly addressed these issues, as we see a statistically significant difference in behavior when comparing the hint and no hints under the Simplified Protocol, suggesting that subjects were paying attention to their instructions. ${ }^{6}$ However, this also suggests that we did not address the central problems of game form recognition. If the instructional changes were sufficient to facilitate recognition of the game form, the subjects would not need an additional hint in order to recognize the weakly dominant strategy.

Result 3: Modifying the instructions to present an isomorphic game applied to an easily understandable setting provides significant improvements in game form recognition.

\footnotetext{
${ }^{5}$ The difference in means is not significant at conventional levels using a t-test of means.

${ }^{6}$ The difference in means is significant at the $5 \%$ level using a t-test of means.
} 
As discussed above, subjects' behavior in the isomorphic battle game demonstrates that subjects are able to recognize the game form when presented in a familiar context. The results from the Battle protocol can be seen in Table 5. Subjects chose the weakly dominant strategy $46 \%$ of the time and close to the weakly dominant strategy $65 \%$ of the time.

The behavior of the community college subjects in this game closely mirrors the behavior of Caltech subjects in the original instructional protocol with no hint; the average behavior of Caltech subjects is not statistically different from the community college subjects in the battle game scenario (Caltech subjects chose the weakly dominant strategy $46 \%$ of the time and approximated the WD strategy $50 \%$ of the time when they received no hint).

Observation: The isomorphic non-abstract instructional procedures generate new biases.

Even in the battle game, the proposed controls were not completely successful. The battle game introduced other sources of biases once subjects fixed their attention on a specific task. Examples of comments that illustrate potential dangers of this practical application of instructions are illustrated in Table 2.

Result 3: Applying the BCG instructions after the presentation of the isomorphic non-abstract game does not provide large improvements in experimental control.

Participation in the battle game prior to the BCG has some affect on performance in the beauty contest game, particularly for those do not receive a hint. The results from the Battle and Simplified Protocol can be seen in Table 5. With no hint, $22 \%$ of subjects approximate a weakly dominant strategy, whereas without the prior administration of the battle game, only $5 \%$ of subjects come close to equilibrium behavior. The difference is statistically significant at the $10 \%$ level. With the hint, $41 \%$ of subjects chose a strategy that approximates a weakly dominant strategy, compared to $32 \%$ when there is no prior administration of the battle game. ${ }^{7}$

This suggests that the prior administration of the battle game may have a weak effect on the facilitation of game recognition. However, the difference between behavior with and without the hint under the Battle and Simplified Protocol is statistically significant at the $10 \%$ level, indicating that the hint continues to have an impact on subjects' behavior. The success of the hint, even under this protocol suggests that substantial problems of game form recognition persist.

Result 4: Subjects do not move gradually in the direction of equilibrium behavior.

While we do see significant improvements when the game is administered in a lessabstract context in the Battle Protocol and for subjects who receive a hint in both the

${ }^{7}$ This difference is not statistically significant. 
Simplified Protocol and the Battle and Simplified Protocol, these changes are not due to subjects choosing lower numbers on average. In fact, the instructional changes have very little impact on the average number chosen by subjects. This suggests that subjects do not gradually converge toward equilibrium. Instead, they either perceive the game form correctly or do not. This can also be seen by examining Figure 1 which shows the distribution of choices in each of the experimental Protocols.

\section{CONCLUDING REMARKS}

When doing game theoretic experiments, it is tempting to interpret failures of game theory to some alternative theory that rests on a presumption about broad and fundamental incapacities of humans to behave strategically. While this alternative theory is not precisely specified, the implication is that humans rely on instincts that are biased and are sufficiently powerful to override any tendency towards game theoretic predictions. Our results suggest that the concept of game form recognition is an intermediate step between game theory and a general theory of cognitive bias and that this intermediate step can be usefully applied as a bridge. What might appear as a lack of subject rationality becomes a failure by the experimenter to implement appropriate controls. Because the concept of game form recognition creates a focus on rather specific features of subject understanding in relation to their environment, it gives some direction to questions concerning controls.

Our study began with the study of a seemingly simple two person "guessing game" (the "beauty contest") with a weakly dominant strategy. Behavior of the game as reported in the literature suggested a resounding rejection of game theory and our motivation was to investigate the replicability and robustness of the result. The results as reported in the literature clearly replicate but are not robust to changes in the instructions. The result reported here is that rejection of game theory can, in the case of the two person "guessing game," be attributed to a failure of subjects to recognize the game form. The problem is more than just a misspecification of the game form, such as playing an imagined game that is structurally different than the game intended by the experimenter. In some cases, the problem extends to a lack of recognition by the subject that a game is involved, or even a complete failure of the subject to pay attention to the instructions. Instructions that appear very simple to an experimenter need not be transparent to the subject. The consequent lack of experimental control can lead to a scientific lack of understanding of the actual experiment that was conducted and incorrect inferences from the data.

The results have implications for experimental methodology. The problem as identified here, resides with instructions and procedures so those are the areas on which any corrective adjustments should focus. However, our experience suggests that it is easier said than done. While appropriate corrections will depend on details of the experiment, we are able to provide some tentative generalizations. Post experiment questionnaires can be useful tools in helping the experimenter understand the subjects’ problems. Clarifying instructions do help but there is no guarantee that it is enough to facilitate the recognition of the game form. Simplification of instructions can help but it might depend substantially on the characteristics of the individual subjects. Similarly, making the game 
less abstract helps with game form recognition, but it may introduce independent dangers of loss of control. In that respect, it might be important to inform the subject that the less abstract features are included to help with the understanding and should not be taken literally. ${ }^{8}$

\footnotetext{
${ }^{8}$ The paper by Cohen, Plott and Levine (1978) in which subjects were given humorous descriptions of variables resulted in incomprehensible results until subjects were told that the descriptions were there for subject enjoyment and had nothing to do with the underlying task. The problem was discovered through an after-experiment questionnaire in which subjects explained choices as their attempt to change the game to one that they thought made more sense given the descriptions of the variables.
} 


\section{REFERENCES}

Bosch D., A., J. G. Montalvo, R. Nagel, and A. Satorra. 2000. "One, Two, (Three), Infinity, ...: Newspaper and Lab Beauty Contest Games”, American Economic Review, 92: $1687-1701$.

Camerer, Colin F. 2003. Behavioral Game Theory: Experiments in Strategic Interaction. Roundtable Series in Behavioral Economics. Princeton: Princeton University Press; New York: Russell Sage Foundation.

Camerer, C., T. Ho, and J. Chong. 2004. "A Cognitive Hierarchy Model of Behavior in Games”, Quarterly Journal of Economics, 119(3): 861-98.

Cohen, L., C. R. Plott and M. E. Levine 2001. "Communication and Agenda Influence: The Chocolate Pizza Design” Reprinted in Charles R. Plott (ed.), Public Economics, Political Processes and Policy Applications: Collected Papers on the Experimental Foundations of Economics and Political Science, Edward Elgar, Cheltenham, UK.

Cooper, D. J., J. H. Kagel. 2003. "Lessons Learned: Generalizing Learning Across Games”, The American Economic Review, 93(2): 202-207

Costa-Gomes M. and Vincent P. Crawford. 2006. "Cognition and Behavior in TwoPerson Guessing Games: An Experimental Study", American Economic Review 96:1737-1768.

Grosskopf, B. and R. Nagel. (2007) “The Two-Person Beauty Contest”, Games and Economic Behavior (forthcoming)

Ho, T., Camerer, C. and K. Weigelt. 1998. "Iterated Dominance and Iterated Best Response in Experimental Beauty Contests", American Economic Review, 88:947-969.

Nagel, R. 1995. "Unraveling in Guessing Games: An Experimental Study”, American Economic Review, 85:1313-1326.

Nagel, R. 1998. “A Survey on Experimental "Beauty-Contest Games: Bounded Rationality and Learning," in Games and Human Behavior, Essays in Honor of Amnon Rapoport. Eds. D. Budescu, I. Erev, and R.Zwick. Publisher: Lawrence Erlbaum Associates, Inc., New Jersey,105-142.

Plott, Charles R. and Kathryn Zeiler, forthcoming, “ Exchange Asymmetries Incorrectly Interpreted as Evidence of Endowment Effect Theory and Prospect Theory?” American Economic Review.

Stahl, D. O. 1996. "Boundedly Rational Rule Learning in a Guessing Game”, Games and Economic Behavior, 16:303.330. 
Stahl, D. O. (1998): "Is step j thinking an arbitrary modeling restriction or a fact of human nature?” Journal of Economic Behavior and Organization, 37:33-51.

Weber, R. A. (2003), "Learning with no feedback in a competitive guessing game”, Games and Economic Behavior, 44:134-144. 


\section{TABLES AND FIGURES}

Table 1: Experiments and Experimental Design

\begin{tabular}{|c|c|c|c|c|c|c|}
\hline Date & Location & Game & Protocol & No Hint & Hint & Total Subjects \\
\hline $11 / 16 / 2006$ & Caltech & BCG & Baseline & 4 & 6 & 22 \\
\hline 11/27/2006 & Caltech & BCG & Baseline & 9 & 9 & 51 \\
\hline $1 / 19 / 2007$ & Caltech & BCG & Baseline & 7 & 4 & 26 \\
\hline 1/23/2007 & Caltech & BCG & Baseline & 6 & 5 & 26 \\
\hline $1 / 25 / 2007$ & U. P F. & BCG & Baseline & 6 & 7 & 34 \\
\hline 2/06/2007-A* & C.College & BCG & Baseline & 9 & 6 & 27 \\
\hline 2/06/2007-B* & C.College & BCG & Baseline & 6 & 5 & 26 \\
\hline 2/06/2007-C* & C.College & BCG & Baseline & 5 & 4 & 24 \\
\hline 3/01/2007-A & C.College & BCG & Simplified & 6 & 6 & 27 \\
\hline 3/01/2007-B & C.College & BCG & Simplified & 5 & 5 & 28 \\
\hline 3/01/2007-C & C.College & BCG & Simplified & 5 & 4 & 24 \\
\hline 3/21/2007-A** & C.College & Battle & Battle & 15 & 15 & 30 \\
\hline 3/21/2007-B*** & C.College & Battle & Battle & 12 & 13 & 25 \\
\hline $4 / 02 / 2007-\mathrm{A}^{* *}$ & C.College & BCG & Simplified & 5 & 4 & 24 \\
\hline \multirow[t]{2}{*}{ 4/02/2007-B*** } & C.College & BCG & Simplified & 5 & 4 & 21 \\
\hline & & & Battle and & & & 25 \\
\hline \multirow[t]{2}{*}{ 4/05/2007-A } & C.College & BCG \& Battle & Simplified & 14 & 11 & \\
\hline & & & Battle and & & & 24 \\
\hline \multirow[t]{2}{*}{ 4/05/2007-B } & C.College & BCG \& Battle & Simplified & 12 & 12 & \\
\hline & & & Battle and & & & 25 \\
\hline $4 / 6 / 2007$ & C.College & BCG \& Battle & Simplified & 13 & 12 & \\
\hline
\end{tabular}

* The questionnaire was administered to these subjects. In the battle experiments, subjects were asked to jot down a brief explanation of their choice on the back of the instructions.

** These two experiments were conducted in the same class. During the first visitation on $3 / 21 / 2007$, the battle experiment was conducted and on the second visitation on 4/02/2007, the BCG was conducted.

*** These two experiments were conducted in the same class. During the first visit on 3/21/2007-B, the battle experiment was conducted and during the second visit on 4/02/2007-B, the BCG was conducted.

Subject totals also include those subjects who participated in a group treatment. The results are not included in this analysis. 


\section{Table 2A. Questionnaire Administered after experiment}

\section{Questionnaire}

\section{Thanks for your help}

We are puzzled about some of the responses to our exercise yesterday. There seemed to be many misconceptions and we would like to find out what they were.

1. Did you misunderstand the situation? What were you thinking?

2. What about the instructions mislead you? What can we do to avoid it?

3. Here are some of our guesses about the nature of the problem. Circle any that apply to you.

(i) I did not really read the instructions.

(ii) I did not know that there was a competition.

(iv) I did not understand how a winner would be chosen.

(v) I did not realize that real money would change hands.

4. Please give us any additional comments that you think might help us. 


\section{Table 2B: Illustrations of Loss of Experimental Control: Comments taken from Questionnaire}

General lack of attention

I was kind of lost. I was not thinking.

I didn’t really understand what was going on. The ending instructions were confusing.

I did not read.

I am stupid. Avoid using stupid people like me.

I misread the instructions.

I understood it was a game but I was trying to figure out what the directions mean since I am not very good at math

I didn't think too much. The $2 / 3$ thing [was confusing]

I didn't read the instructions. Maybe [you should] write bigger font and bold.

I wasn't really paying attention. I didn't understand the how winning number thing I just picked randomly. I did not read the instructions.

I knew the question is a math competition.

Failure to recognize that own reward depended on choice of others - not a game

52: sum of cell phone numbers

I chose 14 cause its my birthday.

favorite number

Failure to understand how winner is determined

I was thinking $2 / 3$ of 100

try and get a close number to the average so that my competitor will have a lower number.

50: since we want the most average number in this game, I picked the perfect average

Because $(50+100) / 2=75$

The lowest \# wins. If you choose "0" it won' t have an effect on the other \# so I choose 1 because it is the lowest \# the how $2 / 3$ thing was unclear

I did not understand the $2 / 3$ thing

I do not know how to get 2/3 of the average.

Incentives failure

don't want to win

I was thinking of homework and food.

Imposing own environment in the battle context

50: middle increases mobility

99: b/c if I get to win this battle, I have $1 \mathrm{ft}$ to put my flag

not the highest so it's not that easy to spot.

0 : no oxygen at the peak of the hill

50: can both attack and defend from my opponent

50: high enough to win the battle but the troop won't get tired on the way to the top 


\section{Table 3: List of Instruction and Procedural Changes}

\section{Baseline Protocol (no hint and hint identical except for hint) \\ Neutral and general language was used.}

\section{Simplified Protocol (suggestive and simple)}

Instructions:

Header was added with a Caltech seal.

Language was changed to use words like "game", "opponent" and "strategy".

Language was simplified and bullet form of instructions used rather than paragraph.

The ratio was changed from $2 / 3$ to $3 / 4$.

The hint was accompanied by a figure.

Protocol:

Experimenters were introduced by instructor who emphasized importance of exercise.

Experimenters wore Caltech t-shirts to emphasize that it was research.

Experiments exposed a large fist full of money.

\section{Battle Protocol (imaginary battle context)}

Instructions:

Subjects told that their choices were not examined individually and to think strategically. The strategic setting was isomorphic to Instruction set B except they were to choose where to place their troops on a hill $[0,100]$ and the winner between subject and opponent is the one who choose the higher location.

Protocol:

Exactly like Streamline BCG Protocol.

\section{Simplified and Battle Protocol (Battle experiment followed by BCG)}

Instructions:

The two sets of instructions were the same as in C and in B.

Protocol:

The protocol was the same as in the Battle Protocol and in the Streamlined Protocol. 
Table 4: All Subjects: Baseline Protocol

\begin{tabular}{|l|l|l|l|l|l|}
\hline Measure & CIT & CIT-Hint & PCC & PCC-Hint & PCC-Battle \\
\hline Share: chose 0 & 0.46 & 0.87 & 0 & 0.07 & 0.46 \\
\hline Share: Chose $<=5$ & 0.50 & 0.87 & 0.15 & 0.13 & 0.65 \\
\hline Average \# Chosen & 23 & 3 & 35 & 31 & 15 \\
\hline N & 26 & 23 & 20 & 15 & 105 \\
\hline
\end{tabular}

Table 5: PCC Subjects

\begin{tabular}{|l|l|l|l|l|l|l|l|}
\hline Measure & $\begin{array}{l}\text { Baseline } \\
\text { Protocol: } \\
\text { No Hint }\end{array}$ & $\begin{array}{l}\text { Baseline } \\
\text { Protocol: } \\
\text { Hint }\end{array}$ & $\begin{array}{l}\text { Simplified } \\
\text { Protocol : } \\
\text { No Hint }\end{array}$ & $\begin{array}{l}\text { Simplified } \\
\text { Protocol : } \\
\text { Hint }\end{array}$ & $\begin{array}{l}\text { Battle } \\
\text { Protocol }\end{array}$ & $\begin{array}{l}\text { Battle and } \\
\text { Simplified } \\
\text { Protocol: } \\
\text { No Hint* }\end{array}$ & $\begin{array}{l}\text { Battle and } \\
\text { Simplified } \\
\text { Protocol: } \\
\text { Hint** }\end{array}$ \\
\hline Share: chose 0 & 0.00 & 0.07 & 0.05 & 0.11 & 0.46 & 0.16 & 0.26 \\
\hline Share: Chose $<=5$ & 0.15 & 0.13 & 0.05 & 0.32 & 0.65 & 0.22 & 0.41 \\
\hline Average \# Chosen & 35 & 31 & 25 & 24 & 15 & 31 & 25 \\
\hline N & 20 & 15 & 20 & 19 & 105 & 45 & 39 \\
\hline
\end{tabular}

* here we report only the simplified data, without the battle data.

In Tables 4 and 5, data from the subjects who participated as part of a three person group is excluded. 
FIGURE 1: Cumulative frequencies of the different treatments with PCC subjects
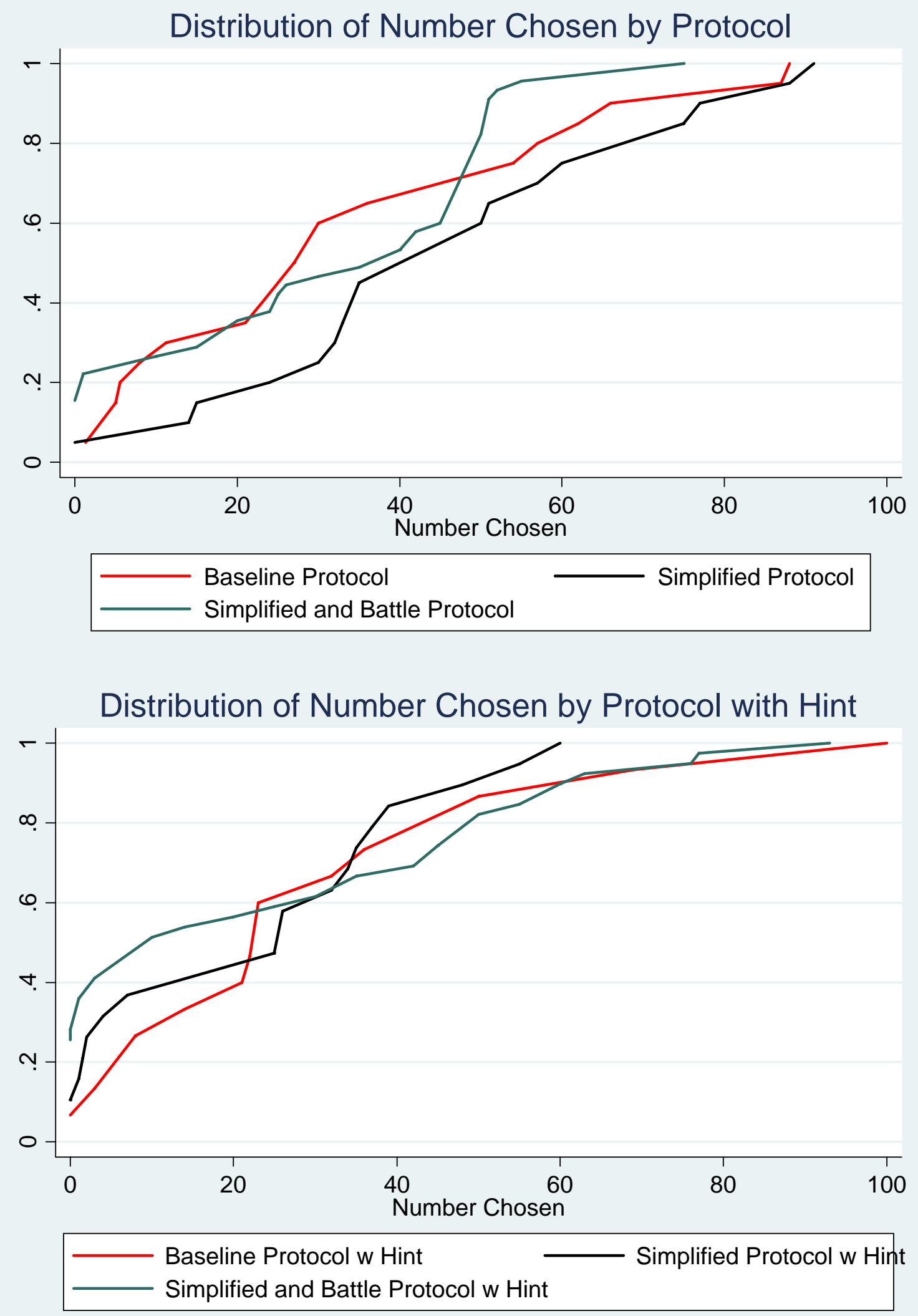


\section{APPENDIX A.}

\section{BASELINE PROTOCOL - HINT}

Your job as a group is to choose a single number between 0 and 100, both included. Your group must choose only ONE number and it need not be an integer. The number you choose will be compared to the number chosen by the group with which you are matched. The winner of the prize is the group whose number is closest to $2 / 3$ times the average of the two numbers. That is, your number and the number of the other group are added and divided by two. The winner of the prize is the group whose number is closest to $2 / 3$ of this average. The losing group gets nothing.

The prize is $\$ 8$ per person ( $\$ 4$ per person if there is a tie). That is, each member of the winning group receives $\$ 8$. If there is a tie, all members of both groups receive $\$ 4$.

You have at most 5 minutes to decide on a single number which you should enter in the blank below.

Notice how simple this is: the lower number will always win (see Figure)

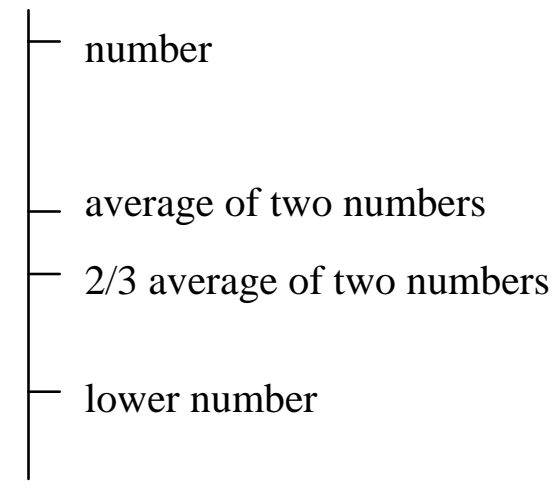

NUMBER CHOSEN _____ (please enter one number here)

Group ID

My Name

Please write down your motives for choosing your number on the back of the instructions. 


\section{BASELINE PROTOCOL - NO HINT}

Your job as a group is to choose a single number between 0 and 100, both included. Your group must choose only ONE number and it need not be an integer. The number you choose will be compared to the number chosen by the group with which you are matched. The winner of the prize is the group whose number is closest to $2 / 3$ times the average of the two numbers. That is, your number and the number of the other group are added and divided by two. The winner of the prize is the group whose number is closest to $2 / 3$ of this average. The losing group gets nothing.

The prize is $\$ 8$ per person ( $\$ 4$ per person if there is a tie). That is, each member of the winning group receives $\$ 8$. If there is a tie, all members of both groups receive $\$ 4$.

You have at most 5 minutes to decide on a single number which you should enter in the blank below.

NUMBER CHOSEN (please enter one number here)

Group ID

My Name

Please write down your motives for choosing your number on the back of the instructions. 


\section{SIMPLIFIED PROTOCOL - HINT}

\section{\begin{tabular}{llll} 
CALIFORNIA INSTITUTE OF TECHNOLOGY \\
\hline
\end{tabular}}

\section{Instruction to the Game:}

1. Strategically choose a number between 0 and 100, both included.

\section{A LT ECH}

2. You will be randomly assigned an opponent from the room.

3. We will calculate $3 / 4$ of the average of your number and your opponent's number

\section{Winning Rule:}

- Your number will win if it is closer to (3/4 of the average of the your number and your opponent's number)

- If your number wins we will pay you $\$ 8$ at the end of class today. If you choose the same number as your opponent, you will receive \$4.

Notice how simple this is: the lower number will always win (see Figure)
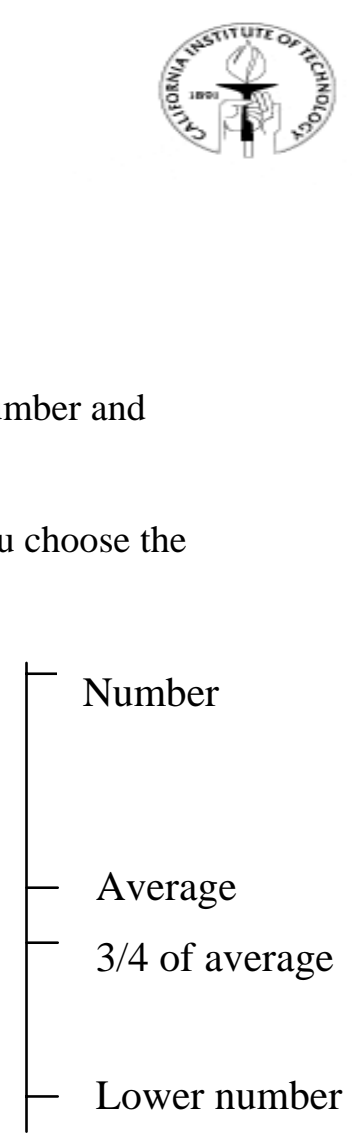

You have five minutes to think about your answer. Write your number in the space below.

NUMBER CHOSEN (please enter one number here)

Group ID

My Name

Please write down your motives for choosing your number on the back of the instructions. 
SIMPLIFIED PROTOCOL- NO HINT

\section{CALIFORNIA INSTITUTE OF TECHNOLOGY}

\section{CALTECH}

\section{Instruction to the Game:}

1. Strategically choose a number between 0 and 100, both included.

2. You will be randomly assigned an opponent from the room.

3. We will calculate $3 / 4$ of the average of your number and your opponent's number

\section{Winning Rule:}

- Your number will win if it is closer to (3/4 of the average of the your number and your opponent's number)

- If your number wins we will pay you $\$ 8$ at the end of class today. If you choose the same number as your opponent, you will receive $\$ 4$.

You have five minutes to think about your answer. Write your number in the space below.

NUMBER CHOSEN (please enter one number here)

Group ID

My Name

Please write down your motives for choosing your number on the back of the instructions. 


\section{BATTLE PROTOCOL}

\section{CALIFORNIA INSTITUTE OF TECHNOLOGY}

You have been chosen to play a simple strategic game. This game is a small part of a larger project, so your performance will not be scrutinized or manipulated. Please think strategically about the scenario below.

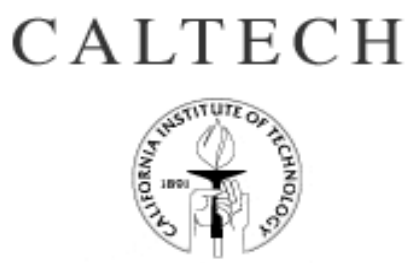

\section{Setting of the Game:}

- Imagine yourself at war facing an opponent in a battle on a hill

- Both you are your opponent (a random person from this room) must locate yourselves on the hill

- The hill is 100 feet high

\section{Instruction to the Game:}

- Your job is to choose how high to locate your troop on the hill, from 0 feet high to 100 feet high (both heights included).

- You win the battle if your chosen location is higher than your opponent's.

\section{Winning Rule:}

- If your location is higher than your opponent's, you will win $\$ 8$ cash at the end of class today. If you choose the same location as your opponent, you will receive $\$ 4$.

You have five minutes to think about your answer. Write your location in the space below.

LOCATION CHOSEN (please enter one number here)

Group ID

My Name \& ID Number

Please write down your motives for choosing your number on the back of the instructions. 